\title{
The Estimation of Zinc in Sea Water using Sodium Diethyldithiocarbamate.
}

\author{
By \\ W. R. G. Atkins, F.I.C., F.R.S., \\ Head of the Department of General Physiology at the Plymouth Laboratory.
}

SEA water contains very little zinc. Values from 0-73 mg. per cubic metre have been cited in Physics of the Earth, V, 180, Washington, 1932. According to Orton it is less than $0 \cdot 1$ parts per million in the English Channel. Dieulafait found $2 \mathrm{mg}$. and Bodansky $7 \cdot 3$, erroneously quoted as 73 above. The method described here permits of the detection of as little as $8 \mathrm{mg}$. per $\mathrm{m}^{3}$ using $200 \mathrm{ml}$. of distilled water in a Hehner tube, the delicacy of the reaction being much greater than that of any other for zinc. Sea water from the English Channel gives no turbidity and so is unlikely to contain as much as $8 \mathrm{mg}$. per $\mathrm{m}^{3}$. The method is brought forward on account of its usefulness in detecting and estimating zinc in sea water contaminated by contact with metallic surfaces. Its use in fresh water has already been described (Analyst, 1935, 60, p. 400, No. 711, June), and to this paper reference may be made for some possible sources of interference and for the origin of the reagent.

The turbidimetric estimation of the zinc is carried out by adding $10 \mathrm{ml}$. of a $0 \cdot 1$ per cent solution of the reagent to Nessler tubes containing suitable concentrations of zinc in neutral solution. Having thus found the approximate concentration, the comparison is completed using Hehner tubes. If concentrated sea water is used a light golden colour appears on account of the copper present. This renders difficult exact comparison with the white standards. The use of a Schott (Jena) filter No. OG2, which is a close match to the colour that appears, gets over this difficulty.

It has long been known that galvanized iron should not be used in marine aquaria. A fish merchant recently used this material for a tank in which to keep lobsters. Though well aerated and not overcrowded the water in this tank rapidly proved fatal, all the animals dying within four days. The water was analysed as described and was found to contain about 25 parts per million of zinc, a concentration about 3,000-10,000 times greater than that found in sea water. It was ascertained by Miss D. M. Mees that small crabs died within four days in sea water containing 25 p.p.m. of zinc, so there is no doubt that the zinc dissolved from the galvanised iron was the cause of the trouble in the lobster tank. 